\title{
Database Design on Resource Transmission System for Philosophy of Science
}

\author{
Zhe $\mathrm{Li}^{1, \mathrm{a}}$, Jiahui Wang ${ }^{2, \mathrm{~b}}$ \\ ${ }^{1}$ College of International Exchange, Bohai University, Jinzhou, 121013, China \\ ${ }^{2}$ College of Information Science and Technology, Bohai University, Jinzhou, 121013, China \\ a503412508@qq.com, b24351108@qq.com
}

\begin{abstract}
Keywords: philosophy of science; resource; database design; resource transmission system; conceptual structure design; logical structure design
\end{abstract}

\begin{abstract}
With the development of science and technology, the study of the philosophy of science also has been subjected to the value more and more. Therefore, more and more philosophy of science resources are demanded, how to allow students to receive more abundant philosophy of science resources and increase students' self-learning ability desiderate to be solved in the field of philosophy of science. Database design in this paper is the groundwork for developing resource transmission system. First, the basic principles of database design were outlined; then, conceptual structure design was conducted. Among them, using E-R diagram to describe relations between entities; finally, logical structure design was carried on, which designed the structure of tables of teacher, student and philosophy of science resource. Contents of this paper have great significance to improve the effectiveness and efficiency of classroom teaching.
\end{abstract}

\section{Introduction}

The philosophy of science is the important branch of philosophy, it main studies the general rule of nature, the basic method of science and technology activities, science and technology and the philosophy issues in the development process and so on. Nowadays, the impact of science and technology on science has become increasingly clear, so the science and technology and social relations become the focus in the research of philosophy of science. Specifically, the further study of philosophy of science will be as high-tech in new generation productivity [1], and the study of the philosophy of science also has been subjected to the value more and more. Therefore, the establishment of resource transmission system for philosophy of science is imperative, so that people can easily learn and better understand the philosophy of science.

Resource transmission system overcomes the time limitation of classroom teaching, students not only learn in the classroom, but also can study after-school according to the resources transferred. The system can increase the students' self-learning opportunities and enable students to receive more enrich and more vivid resources in addition to textbooks to improve teaching effectiveness and efficiency. Simultaneously, it provides instant interaction interface for teachers and students to learn, not only to help teachers to complete the task of teaching, but also can guide students to complete the task. In addition, the transmission system facilitates the communication between teachers and students, so it can improve the work efficiency of teachers and avoid spending unnecessary time. This transmission system has brought a series of changes, and it will help improve its overall management level.

\section{Database Design Principles}

Database design is an important part of the development and construction of modern information system. According to the three models of database to carry on database design (the internal model, the conceptual model and the external model), the design process includes requirement analysis, conceptual structure design, logical structure design, physical design and database implementation and maintenance [2]. Specific database design process shows in Fig. 1. 


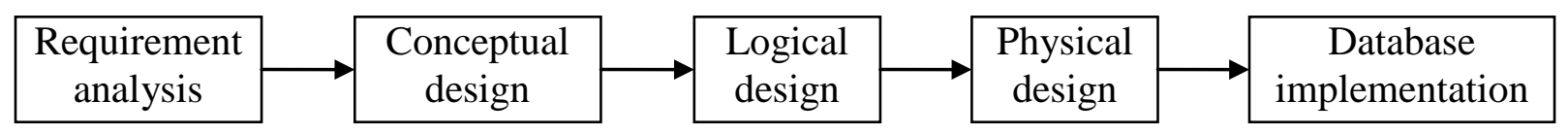

Fig. 1. Database design flow chart

Resource transmission system is inseparable from the support of database system, and the database is the core and foundation of information system. Large amounts of data in information system are organized according to a certain model, it can storage, maintain and retrieve data, so that information system can obtain the necessary information from the database easily, timely and accurately. So whether it is the teacher' information, student' information, or philosophy of science resource' information and all of them need to be stored in the database, and the database exists independently of the program, so it has better security. Database design principles of the system are as follows:

(1) Standardized design must be carried on to minimize data redundancy and duplication. On the premise of meeting the demand, reasonable database table should have the minimum data duplication to reduce redundant data. The name lengths of database objects are not more than 30 characters, it is easy for applications to adapt to different databases.

(2) Structure design and operation design are combined to conduct. When designing the database structure, sometimes we often increase the number of redundant data deliberately in order to achieve a simple programming. Although this is contrary to the traditional relational database theory, if the increased redundancy can not significantly increase the storage space and reduce efficiency, and can help to realize programming, you can use this method.

(3) Consistency and integrity of data. In order to ensure consistency and integrity of the database, designers often design too much tables' correlations as much as possible to reduce data redundancy. However, the table' correlation is a mandatory measure, and while inserting, updating, deleting parent and child tables after establishment, these operations are taking up the cost of the system. If data redundancy is low, the integrity of data can be easy ensured, but it increases the operations of query among tables. Therefore, in order to improve the response time of the system, reasonable data redundancy is necessary [3].

(4) Using cursor carefully. For the cursor defined by multi-table and a large table, using the cursor to traverse the data line by line, it is easy getting into the long wait even a crash situation, so when using a cursor, we can consider to establish a temporary table. You can put the eligible rows of data into a temporary table, then define a cursor on a temporary table to operate, so the performance will be significantly improved.

\section{Conceptual Structure Design}

User application requirement described by requirement analysis is the specific requirement in the real world, the user requirement in the process of requirement analysis needs to be abstracted as information structure, so the process of conceptual model is the conceptual structure design [4]. Conceptual model is information structure that each user in organization concerns, it must be independent of any computer data model [5]. Conceptual structure design is modeling for information world, conceptual model commonly used is E-R model. E-R model, which was put forward by P.P.S.Chen in 1976, has become a major tool for conceptual structure design. There are three entities in the system, namely "teacher, student and philosophy of science resource." Among them, the entity of "teacher" and the entity of "philosophy of science resource" has the relationship of many to many, that is a "teacher" can upload multiple "philosophy of science resources" and a" philosophy of science resource" could also be uploaded by a number of "teachers"; the entity of "student" and the entity of "philosophy of science resource" has the relationship many to many, namely a "student" can download more " philosophy of science resources" and a "philosophy of science resource" may be downloaded by more than one "student". According to the relationship between the entities, the conceptual model structure of the system shows in Fig. 2. 


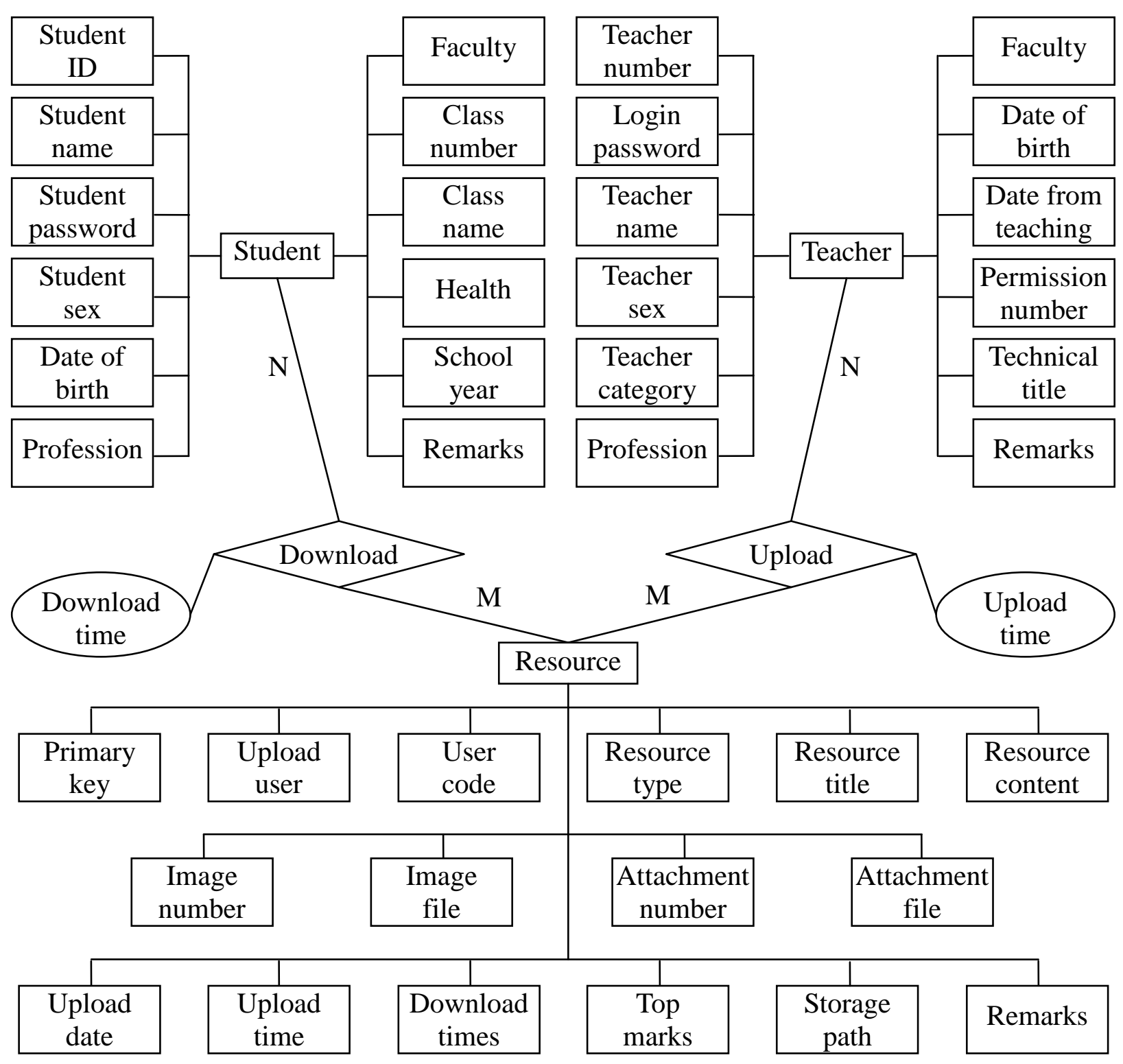

Fig. 2. E-R diagram of system

\section{Logical Structure Design}

Logical structure design can be simply understood as that an abstract concept structure can be converted to a specific data model supported by database products, such as the relational model, and then optimize it. Results of database logical design are not unique, in order to further improve the performance of database application system, the structure of the data model should also be modified appropriately to improve query speed [6,7]. The goal of database logical design is to meet the users' requirements for integrity and security, so it can support the operation of a variety of database transactions efficiently in logical level. Therefore, the process of logical structure design can be simplified to that E-R diagram can be translated into the relational model to format a database logic model; then according to users' requirements and considerations of safety, the necessary view is established based on the basic tables to format the external model of data. The conversion process is actually that the entities, the entities' attributes and the relationships among entities are converted into relational model, and the conversion generally follows the following principles:

(1) An entity type is converted to a relational model. The attributes of entities are the attributes of relationships. The codes of entities are the codes of relationships. 
(2) A relationship of m:n can be converted to a relational model. The codes of entities connected with the relationship and relationship's own attributes are converted to the attributes of relationship. The codes of relationship are the combination of the codes of all entities. The relationship between the codes as a combination of entities codes.

(3) A multi-relationship among three or more entities can be converted to a relational model. The codes of entities connected with the multi-relationship and relationship's own attributes are converted to the attributes of relationship. The codes of relationship are the combination of the codes of all entities.

(4) A relationship of 1:1 can be converted to an independent relational model, and it can also merge with either end of the corresponding relational model. According to the previous requirement analysis and conceptual structure design, database structure tables of the system were designed as follows:

Teacher (teacher number, login password, teacher name, teacher sex, date of birth, faculty, date from teaching, permission number, teacher category, technical title, profession, remarks)

Student (student ID, student password, student name, student sex, date of birth, profession, faculty, class number, class name, health, school year, teacher number, teacher, remarks)

philosophy of science resource (primary key, upload user, user code, resource type, resource title, resource content, image number, image file, attachment number, attachment file, upload date, upload time, download times, top marks, storage path, remarks)

\section{Conclusion}

In summary, the construction of resource transmission system has become a necessary mean and necessary way to seek high-level development in the field of philosophy of science, and the construction of its database is the basis work for building resource transmission system. According to internal model, conceptual model and external model to build database of resource transmission system for philosophy of science, so the database design process was described, including requirement analysis, conceptual structure design, logical structure design, physical design, database implementation and maintenance. In order to ensure the efficiency, easy-to-use and stabilization of database system, so certain design principles must be followed in the process of database design, and the system follows five design principles described above. Only select the appropriate design methods, you can get better design effect. The design of the database system in this paper laid the foundation for the development of resource transmission system.

\section{Acknowledgement}

This work is supported by social science fund project of Liaoning province (L14DGL044): Research on Effect evaluation and optimization mechanism for urban and rural compulsory education teacher balanced allocation policy; "Twelfth Five Year" planning project of Liaoning education and science (JG15ZXY15): Research on Effect evaluation and optimization mechanism for policy implementation of "special post teachers" in rural areas; 2016 annual economic and social development project in Liaoning province (2016lslktzixlx-01): Formation mechanism and countermeasure research the classroom' phubbing in colleges and universities in Liaoning.

\section{References}

[1] W. X. Hu, "A Review of Domestic Studies on Philosophy of Science and Technology (1976-2012)," Studies on Mao Zedong and Deng Xiaoping Theories, vol. 20, no. 6, pp. 46-53, 2013.

[2] Z. Y. Wang, N. Chen, "Enterprise Database Design Based on Information Technology," Commercial Times, vol. 29, no. 5, pp. 67-68, 2010. 
[3] F. B. Fang, K. R. Yao, "Talking About the Object-Oriented Database Design," Journal of Yangtze University, vol. 6, no. 2, pp. 263-264, 2009.

[4] Baidu Encyclopedia, "Conceptual Structure Design," http://baike.baidu.com/view/1638403.htm, 2014-8-27.

[5] L. Zhang, L. Ma, "Database Design," Journal of Anyang Institute of Technology, vol. 6, no. 4, pp. 76-79, 2007.

[6] H. M. Chen, "Logic Structure Design of Database Design," Fujian Computer, vol. 28, no. 10, pp. 214-215, 2012.

[7] Ken England, Gavin Powell, "Logical Database Design for Performance," Microsoft SQL Server 2005 Performance Optimization and Tuning Handbook, 2007. 